\title{
Additive allometric model of Quercus spp. stand biomass for Eurasia
}

\author{
Vladimir Andreevich Usoltsev ${ }^{1,2}$, Seyed Omid Reza Shobairi ${ }^{3 *}$, Viktor Petrovich Chasovskikh ${ }^{1}$
}

\author{
${ }^{1}$ Ural State Forest Engineering University, 620100 Yekaterinburg, Sibirskiy Trakt, 37, Russia \\ ${ }^{2}$ Botanical Garden of Ural Branch of RAS, 620144 Yekaterinburg, 8 Marta Str., 202a, Russia \\ ${ }^{3}$ Nanjing University of Information Science and Technology, No.219, Ningliu Road, Nanjing, Jiangsu, \\ China (Postcode: 210044) \\ *corresponding author's e-mail: Omidshobeyri214@gmail.com \\ Received: 21 March 2020 / Accepted: 15 April 2020
}

\begin{abstract}
When using the unique in terms of the volume of database on the level of stand of the genus Quercus, the trans-Eurasian additive allometric models of biomass of stands for Eurasian Quercus forests are developed for the first time, and thereby the combined problem of model additivity and generality is solved. The additive model of forest biomass of Quercus is harmonized in two ways: it eliminated the internal contradictions of the component and the total biomass equations, and in addition, it takes into account regional differences of forest stands not only on total, aboveground and underground biomass, but also on its component structure, i.e. it reflects the regional peculiarities of the component structure of biomass.
\end{abstract}

Keywords: model's harmonizing, dummy variables, biological productivity, biomass of forests, genus Quercus, sample plots.

\section{Introduction}

In recent years, the world forest ecology is experiencing unprecedented information splash in the assessment of forest biological productivity in relation to climate change observed since 1960-80-ies (Budyko, 1977). The current hype surrounding the problem of breached the carbon balance of the biosphere passes into the common paradigm of sustainable development, which the first is biosphere-stabilizing function of forests, but traditional resource forest management is seen as a subordinate task (Utkin, 1995). Estimating of biological productivity or carbon-depositing ability of forests is going on the global level, and its increase is one of the major factors of climate stabilization.

The modern methods of modelling the biological productivity of trees and tree stands have been developed towards additivity of biomass components (Bi et al., 2010; Dong et al., 2015) and towards transition from "pseudo- generic" allometric models to really generic, involving regionalization of biomass model by introducing dummy variables (Fu et al., 2012), that usually fulfilled on local sets of actual biomass of trees and tree stands. Because different biomass components are characterized by different rates both their growth and mortality, they make a different contribution to matter cycling in the forest ecosystem and should be estimated not only in total but also separately. Information on component composition of forest biomass was needed in other applications too, in particular, when assessing fire danger and modelling of forest fires (DeMiguel et al., 2014). Additivity of biomass components supposes that the total biomass (stem, branches, foliage, roots), obtained from component equations, should be equal (but usually not equal) to the value obtained using the equation for total biomass. We generated the database of forest stand biomass for the main forest species in Eurasia (Usoltsev, 2010; Usoltsev, 2013), that has enabled these 
modern methodologies to be implemented on the entirely different, higher level, namely on modelling additive biomass according to transcontinental level.

In this article, the first attempt to develop transcontinental harmonized allometric model of vicar species oak (genus Quercus) forest stand biomass, which combine both mentioned by Jacobs and Cunia (1980) approaches, namely, ensuring the principle of additivity of biomass component composition and localizing of biomass additive model on regions of Eurasia by introducing dummy variables. In other words, an attempt is made to solve the problems of combining additivity and totality of models. These models will provide the basis for the development of transcontinental regional standards for evaluation biomass of forest stands.

\section{Material and methods}

Of the database mentioned the material in a number of 367 sample plots with estimations of Quercus forest stand biomass (t/ha) is extracted. Genus Quercus is introduced by five vicarage species (correspondingly $Q$. robur L., $Q$. petraea (Matt.) Liebl., Q. mongolica Fisch. ex Ledeb., $Q$. mongolica subsp. crispula (Blume) Menitsky and $Q$. glauca Thunb.), distributed across 6 eco-regions and designated respectively with the 6 dummy variables from $X_{0}$ to $X_{5}$ (Table 1).

Analysis of biomass forest stands is made on the basis of allometric additive models. According to the struc- ture of disaggregation three-step model (Tang et al., 2000; Dong et al., 2015), biomass value, estimated by the total biomass equation, exploded into components according to the scheme presented in Figure 1. The coefficients of the regression models for all three steps are evaluated simultaneously, which ensures additivity of biomass of all the components - total, intermediate (steps 1 and 2) and initial (step 3a,b) (Dong et al., 2015).

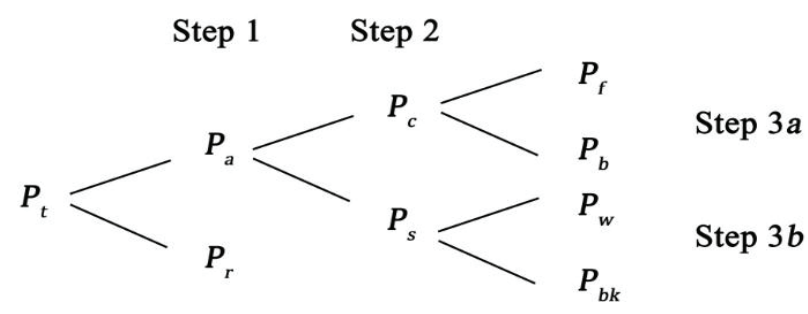

Figure 1. The pattern of disaggregating three-step proportional weighting additive model. Designation: $P t, P r, P a, P c$, $P s, P f, P b, P w$ and $P b k$ are stand biomass respectively: total, underground (roots), aboveground, crown (leaves and branches), stems above bark (wood and bark), needles, branches, stem wood and stem bark correspondingly, $t$ per ha

The distribution of sample plots, on which the oak forest biomass is measured in ecoregions of Eurasia, is shown in Figure 2.

Table 1. The encoding scheme of the regional actual biomass data sets of 367 Quercus stands

\begin{tabular}{|c|c|c|c|c|c|c|c|c|c|c|c|}
\hline \multirow{2}{*}{$\begin{array}{l}\text { Eco- } \\
\text { region* }\end{array}$} & \multirow{2}{*}{$\begin{array}{l}\text { Species** of } \\
\text { Quercus }\end{array}$} & \multicolumn{5}{|c|}{$\begin{array}{l}\text { Block of dummy } \\
\text { variables }\end{array}$} & \multirow{2}{*}{$\begin{array}{l}\text { stand } \\
\text { age, } \\
\text { yrs }\end{array}$} & \multicolumn{2}{|c|}{ Ranges of: } & \multirow{2}{*}{$\begin{array}{c}\text { mean } \\
\text { height, } \\
\mathrm{m}\end{array}$} & \multirow{2}{*}{$\begin{array}{c}\text { Plot } \\
\text { quantity }\end{array}$} \\
\hline & & $X_{1}$ & $X_{2}$ & $X_{3}$ & $X_{4}$ & $X_{5}$ & & & & & \\
\hline WCE & Q. robur $\mathrm{L}$. & 0 & 0 & 0 & 0 & 0 & $5 \div 220$ & $0.166 \div 7.00$ & $0.9 \div 55.3$ & $2.0 \div 32.8$ & 170 \\
\hline WCE & Q. petraea (Matt.) Liebl. & 1 & 0 & 0 & 0 & 0 & $17 \div 140$ & $0.163 \div 14.92$ & $2.3 \div 46.7$ & $3.2 \div 28.8$ & 26 \\
\hline ERn & Q. robur $\mathrm{L}$. & 0 & 1 & 0 & 0 & 0 & $10 \div 280$ & $0.129 \div 41.19$ & $1.5 \div 70.0$ & $2.2 \div 32.4$ & 110 \\
\hline ERs & Q. robur $\mathrm{L}$. & 0 & 0 & 1 & 0 & 0 & $15 \div 60$ & $0.427 \div 5.67$ & $3.9 \div 23.1$ & $4.2 \div 21.5$ & 46 \\
\hline SFE & $\begin{array}{l}\text { Q. mongolica Fisch. } \\
\text { ex Ledeb. }\end{array}$ & 0 & 0 & 0 & 1 & 0 & $38 \div 190$ & $1.116 \div 4.91$ & $6.7 \div 28.8$ & $6.2 \div 19.8$ & 6 \\
\hline Jap & $\begin{array}{l}\text { Q. mongolica subsp. } \\
\text { crispula (Blume) } \\
\text { Menitsky } \\
\text { Q. glauca Thunb. }\end{array}$ & 0 & 0 & 0 & 0 & 1 & $4 \div 80$ & $0.917 \div 6.78$ & $4.2 \div 18.9$ & $4.3 \div 11.5$ & 9 \\
\hline
\end{tabular}

\footnotetext{
* Designates of regions hereinafter: WCE - Western and Central Europe; ERn - European Russia, northern part; ERs - European Russia, southern part; SFE - South of Far East, Primorie; Jap - Japanese islands.

**nomenclature according to World Flora Online. An Outline Flora of All Known Plants. http://www.worldfloraonline.org
} 


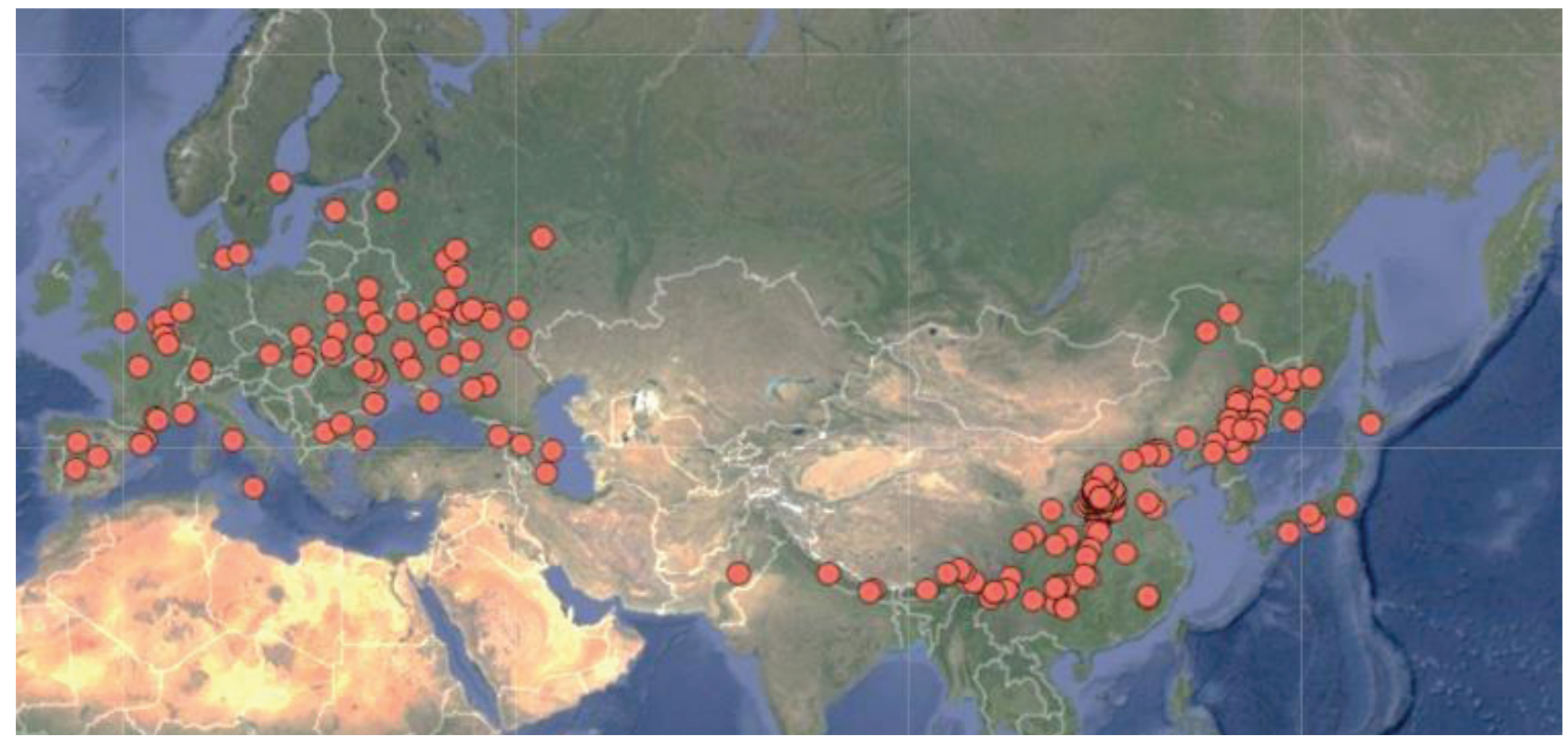

Figure 2. Allocation of sample plots with measured biomass ( $\mathrm{t} / \mathrm{ha}$ ) of 367 stands of oak (genus Quercus) on the territory of Eurasia

\section{Results and discussion}

The initial allometric model is calculated;

$$
\begin{aligned}
& \ln P_{i}=a_{i}+b_{i}(\ln A)+c_{i}(\ln A)^{2}+d_{i}(\ln H)+e_{i}(\ln D)+ \\
& +f_{i}(\ln N)+\Sigma g_{i j} X_{j},
\end{aligned}
$$

where $P i$ - biomass of $i$-th component, t per ha; $A$ - stand age, years; $H$ - mean stand height, $\mathrm{m} ; D$ - mean tree diameter, cm; $N$ - tree number, 1000/ha; $a-g-$ regression coefficients; $i$ - index of biomass component: total (t), aboveground (a), roots (r), crowns (c), stems above bark (s), needles (f), branches (b), stem wood (w) and stem bark (bk); $j$ - index (code) in the block of dummy variables coding the eco-regions, from 0 to 5 (see Table 1).

Model (1) after anti-log transformation is given to the form:

$P_{i}=a_{i} A^{b i} A^{c i(\ln A)} H^{d i} D^{e i} N^{f i} e^{\Sigma g i j X j}$

Characteristic of equations (1) obtained by its approximation using actual biomass data, after the introduction of correction to the logarithmic transformation after Baskerville (1972) and the subsequent anti-log transformation to (2) are given in the Table 2. All the regression coefficients of the equations (2) with numerical variables are significant at the level of probability of 0.95 or higher, and the equations are adequate to actual data.

The equations (2) are modified according to the algorithm proposed by Dong et al. (2015) (Table 3), and the final transcontinental additive model of oak biomass com- ponent composition on the level of forest stand is given in the Table 4. The model is valid in the range of actual data of stand age, mean tree height, mean stem diameter and tree density, listed in the Table 1, and is characterized by a double harmonization: one of which provides the principle of biomass component additivity, and the second one relates to the introduction of dummy variables, localizing the model according to ecoregions of Eurasia.

At the next stage of the study a comparison of the adequacy of additive model (Table 4) and independent equations shown in the Table 2. For their correct comparing the sample plots with incomplete biomass component structure are deleted from the initial harvest data, i.e. only those records are left in which the data are available on both aboveground and underground biomass. The equations (2) are approximated according to such "methodized" data, and their final forms are given in the Table 5. As the "methodized" additive model, and "methodized" independent equations, are tabulated according to actual mass-forming indices of the modified data and the obtained values are compared with harvest biomass data using the formula:

$R^{2}=1-\frac{\sum_{i=1}^{N}\left(Y_{i-} \hat{Y}_{i}\right)^{2}}{\sum_{i=1}^{N}\left(Y_{i-} \bar{Y}_{i}\right)^{2}}$

where $Y_{i}$ is observed value; $\hat{Y}_{i}$ is predicted value; $\bar{Y}$ is the mean of $N$ observed values for the same component.

The results of comparison of the adequacy of two modeling methods are summarized in the Table 6 and they indicate that the adequacy of the two systems of equations for 
aboveground biomass, underground one and stem biomass are similar.

The ratio of actual values and derived ones by tabulating independent and additive stand biomass models (Fig. 3) shows the degree of correlativeness of the actual and calculated values and, in many cases, the absence of visible differences in the structure of residual variances obtained on two named models. More or less the value of $\mathrm{R}^{2}$ of one or the other model is determined by the random position of actual values of maximum stand biomass in confidence range and uneven dispersion, namely accidental because of their small number and the greatest contribution to the residual variance (see Fig. 3).

Table 2. Characteristic of initial allometric equations for Quercus stands

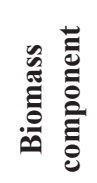

Independent variables and the regression model coefficients

$\operatorname{adj} R^{2}$

\begin{tabular}{|c|c|c|c|c|c|c|c|c|c|c|c|}
\hline$P_{t}$ & 1.3132 & $A^{0.2782}$ & $H^{0.2576}$ & $D^{1.0297}$ & $N^{0.4448}$ & $\mathrm{e}^{0.1913 X 1}$ & $\mathrm{e}^{0.1274 X 2}$ & $\mathrm{e}^{0.4569 X 3}$ & $\mathrm{e}^{0.1768 X 4}$ & $\mathrm{e}^{0.6994 X 5}$ & 0.838 \\
\hline \multicolumn{12}{|c|}{ Step 1} \\
\hline$P_{a}$ & 0.4328 & $A^{0.2485}$ & $H^{0.6724}$ & $D^{1.0102}$ & $N^{0.5023}$ & $\mathrm{e}^{0.0990 X I}$ & $\mathrm{e}^{-0.0216 X 2}$ & $\mathrm{e}^{0.0113 X 3}$ & $\mathrm{e}^{-0.0220 X 4}$ & $\mathrm{e}^{0.4872 X 5}$ & 0.905 \\
\hline$P_{r}$ & 0.7962 & $A^{0.5019}$ & $H^{-0.4864}$ & $D^{1.0320}$ & $N^{0.4851}$ & $\mathrm{e}^{0.1441 X 1}$ & $\mathrm{e}^{0.2090 X 2}$ & $\mathrm{e}^{1.1347 X 3}$ & $\mathrm{e}^{0.5303 X 4}$ & $\mathrm{e}^{0.3496 X 5}$ & 0.376 \\
\hline \multicolumn{12}{|c|}{ Step 2} \\
\hline$P_{c}$ & 0.7826 & $A^{0.2046}$ & $H^{-0.0329}$ & $D^{0.9848}$ & $N^{0.2594}$ & $\mathrm{e}^{0.2517 X 1}$ & $\mathrm{e}^{-0.0464 X 2}$ & $\mathrm{e}^{-0.2080 X 3}$ & $\mathrm{e}^{-0.1216 X 4}$ & $\mathrm{e}^{0.6319 X 5}$ & 0.701 \\
\hline$P_{s}$ & 0.1801 & $A^{0.2552}$ & $H^{0.8867}$ & $D^{1.0191}$ & $N^{0.5759}$ & $\mathrm{e}^{0.0574 X 1}$ & $\mathrm{e}^{-0.0054 X 2}$ & $\mathrm{e}^{0.0450 X 3}$ & $\mathrm{e}^{-0.0579 X 4}$ & $\mathrm{e}^{0.4558 \times 5}$ & 0.906 \\
\hline \multicolumn{12}{|c|}{ Step 3a } \\
\hline$P_{f}$ & 0.1914 & $A^{0.2036}$ & $H^{-0.0256}$ & $D^{0.7592}$ & $N^{0.4593}$ & $\mathrm{e}^{0.0914 X 1}$ & $\mathrm{e}^{0.0231 X 2}$ & $\mathrm{e}^{-0.0935 X 3}$ & $\mathrm{e}^{-0.1029 X 4}$ & $\mathrm{e}^{0.1904 X 5}$ & 0.403 \\
\hline$P_{b}$ & 0.5635 & $A^{0.1757}$ & $H^{0.0475}$ & $D^{1.0089}$ & $N^{0.2139}$ & $\mathrm{e}^{0.2846 X 1}$ & $\mathrm{e}^{-0.0748 X 2}$ & $\mathrm{e}^{-0.2060 X 3}$ & $\mathrm{e}^{-0.2028 X 4}$ & $\mathrm{e}^{0.7511 X 5}$ & 0.716 \\
\hline \multicolumn{12}{|c|}{ Step 3b } \\
\hline$P_{w}$ & 0.0858 & $A^{0.2494}$ & $H^{1.0440}$ & $D^{1.0714}$ & $N^{0.6450}$ & $\mathrm{e}^{0.1402 X 1}$ & $\mathrm{e}^{0.0471 X 2}$ & $\mathrm{e}^{0.1680 X 3}$ & $\mathrm{e}^{-0.0067 X 4}$ & $\mathrm{e}^{0.6508 \times 5}$ & 0.905 \\
\hline$P_{b k}$ & 0.0446 & $A^{0.4244}$ & $H^{0.2712}$ & $D^{1.2246}$ & $N^{0.6314}$ & $\mathrm{e}^{-0.0658 X 1}$ & $\mathrm{e}^{-0.1520 X 2}$ & $\mathrm{e}^{-0.4354 X 3}$ & $\mathrm{e}^{0.0362 X 4}$ & $\mathrm{e}^{-0.0696 X 5}$ & 0.851 \\
\hline
\end{tabular}

Table 3. The structure of three-step additive model built by proportional weighting (Dong et al., 2015). Symbols here and further see Figure 1 and equation (1)

Step 1

Step 2

Step $3 a$

Step $3 b$

$$
\begin{aligned}
& P_{a}=\frac{1}{1+\frac{a_{r} D^{b_{r}} H^{c_{r}}}{a_{a} D^{b_{a}} H^{c_{a}}}} \times P_{\mathrm{t}} \\
& P_{r}=\frac{1}{1+\frac{a_{r} D^{b_{r}} H^{c_{r}}}{a_{a} D^{b_{a}} H^{c_{a}}}} \times P_{t} \\
& P_{c}=\frac{1}{1+\frac{a_{s} D^{D_{s}} H^{c_{s}}}{a_{c} D^{D_{c}} H^{c_{c}}}} \times P_{a} \\
& P_{s}=\frac{1}{1+\frac{a_{c} D^{b_{c}} H^{c_{c}}}{a_{s} D^{D_{s}} H^{c_{s}}}} \times P_{a} \\
& P_{f}=\frac{1}{1+\frac{a_{b} D^{b_{D}} H^{c_{b}}}{a_{f} D^{D^{\prime} / H^{c_{f}}}}} \times P_{c} \\
& P_{b}=\frac{1}{1+\frac{a_{f} D^{b_{f}} H^{c_{f}}}{a_{b} D^{b_{b}} H^{c_{b}}}} \times P_{c} \\
& P_{w}=\frac{1}{1+\frac{a_{b k} D^{b_{b k}} H^{c_{b k}}}{a_{w} D^{b_{w}} H^{c_{w}}}} \times P_{s} \\
& P_{b k}=\frac{1}{1+\frac{a_{w} D^{b_{w}} H^{c_{w}}}{a_{b k} D^{b_{b k}} H^{c_{b k}}}} \times P_{s}
\end{aligned}
$$


Table 4. Three-step additive model of biomass component composition for Quercus forest stands, built by proportional weighing.

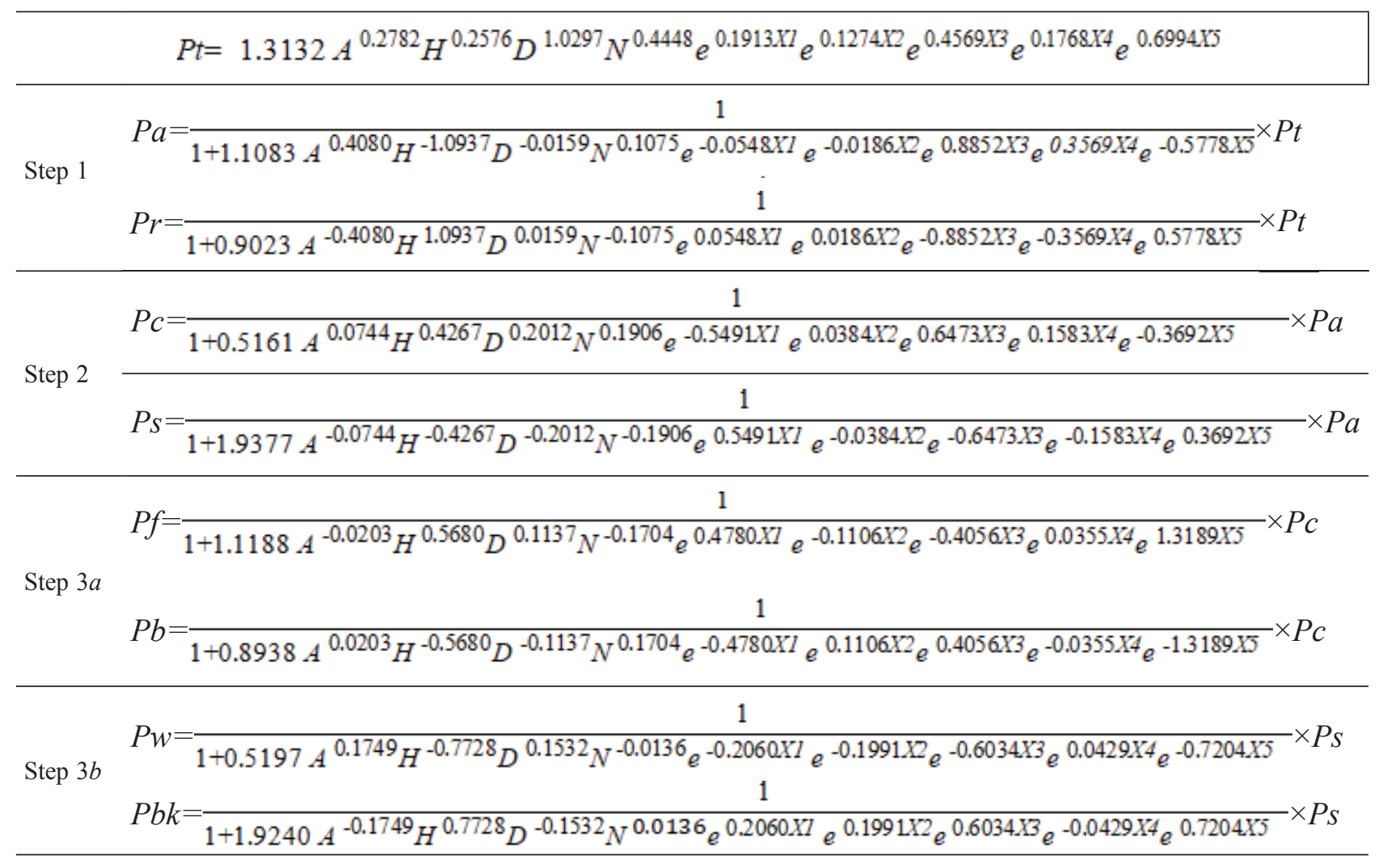

Table 5. The characteristics of "methodized" independent allometric equations for Quercus stands.

\begin{tabular}{|c|c|c|c|c|c|c|c|c|c|c|c|}
\hline \multirow{2}{*}{ 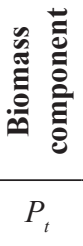 } & \multicolumn{10}{|c|}{ Independent variables and the regression coefficients of the model } & \multirow{2}{*}{$\begin{array}{c}\boldsymbol{a d j} \boldsymbol{R}^{2} \\
0.838\end{array}$} \\
\hline & 1.3132 & $A^{0.2782}$ & $H^{0.2576}$ & $D^{1.0297}$ & $N^{0.4448}$ & $\mathrm{e}^{0.1913 X 1}$ & $\mathrm{e}^{0.1274 X 2}$ & $\mathrm{e}^{0.4569 X 3}$ & $\mathrm{e}^{0.1768 X 4}$ & $\mathrm{e}^{0.6994 X 5}$ & \\
\hline \multicolumn{12}{|c|}{ Step 1} \\
\hline $\mathrm{P}_{\mathrm{a}}$ & 0.6902 & $A^{0.1988}$ & $H^{0.5292}$ & $D^{1.0256}$ & $N^{0.4270}$ & $\mathrm{e}^{0.2022 X I}$ & $\mathrm{e}^{0.0782 X 2}$ & $\mathrm{e}^{0.2566 X 3}$ & $\mathrm{e}^{0.0937 X 4}$ & $\mathrm{e}^{0.8562 X 5}$ & 0.886 \\
\hline$P_{r}$ & 0.7649 & $A^{0.6067}$ & $H^{-0.5645}$ & $D^{1.0096}$ & $N^{0.5345}$ & $\mathrm{e}^{0.1474 X I}$ & $\mathrm{e}^{0.0596 X 2}$ & $\mathrm{e}^{1.1419 X 3}$ & $\mathrm{e}^{0.4506 \times 4}$ & $\mathrm{e}^{0.2784 X 5}$ & 0.376 \\
\hline \multicolumn{12}{|c|}{ Step 2} \\
\hline$P_{c}$ & 0.6916 & $A^{0.1242}$ & $H^{0.1710}$ & $D^{0.9070}$ & $N^{0.2832}$ & $\mathrm{e}^{0.6328 X I}$ & $\mathrm{e}^{0.0668 X 2}$ & $\mathrm{e}^{-0.2691 X 3}$ & $\mathrm{e}^{-0.0123 X 4}$ & $\mathrm{e}^{1.1285 X 5}$ & 0.627 \\
\hline$P_{s}$ & 0.3569 & $A^{0.1986}$ & $H^{0.5977}$ & $D^{1.1082}$ & $N^{0.4738}$ & $\mathrm{e}^{0.0837 X 1}$ & $\mathrm{e}^{0.1052 X 2}$ & $\mathrm{e}^{0.3782 X 3}$ & $\mathrm{e}^{0.1459 X 4}$ & $\mathrm{e}^{0.7593 X 5}$ & 0.900 \\
\hline \multicolumn{12}{|c|}{ Step 3a } \\
\hline$P_{f}$ & 0.3497 & $A^{0.1277}$ & $H^{-0.2342}$ & $D^{0.8072}$ & $N^{0.4222}$ & $\mathrm{e}^{0.1817 X I}$ & $\mathrm{e}^{0.1405 X 2}$ & $\mathrm{e}^{0.0908 X 3}$ & $\mathrm{e}^{0.0037 X 4}$ & $\mathrm{e}^{0.0145 X 5}$ & 0.254 \\
\hline$P_{b}$ & 0.3912 & $A^{0.1074}$ & $H^{0.3338}$ & $D^{0.9208}$ & $N^{0.2518}$ & $\mathrm{e}^{0.6598 X I}$ & $\mathrm{e}^{0.0300 X 2}$ & $\mathrm{e}^{-0.3148 X 3}$ & $\mathrm{e}^{0.0392 X 4}$ & $\mathrm{e}^{1.3335 X 5}$ & 0.658 \\
\hline \multicolumn{12}{|c|}{ Step $3 b$} \\
\hline $\mathrm{P}_{\mathrm{w}}$ & 0.0858 & $A^{0.2494}$ & $H^{1.0440}$ & $D^{1.0714}$ & $N^{0.6450}$ & $\mathrm{e}^{0.1402 X I}$ & $\mathrm{e}^{0.0471 X 2}$ & $\mathrm{e}^{0.1680 X 3}$ & $\mathrm{e}^{-0.0067 X 4}$ & $\mathrm{e}^{0.6508 \times 5}$ & 0.905 \\
\hline$P_{b k}$ & 0.0446 & $A^{0.4244}$ & $H^{0.2712}$ & $D^{1.2246}$ & $N^{0.6314}$ & $\mathrm{e}^{-0.0658 X I}$ & $\mathrm{e}^{-0.1520 X 2}$ & $e^{-0.4354 X 3}$ & $\mathrm{e}^{0.0362 X 4}$ & $\mathrm{e}^{-0.0696 X 5}$ & 0.851 \\
\hline
\end{tabular}


Table 6. The comparison of adequacy indices of independent and additive equations for Quercus stand biomass calculated with their regionalization by introducing dummy variables

\begin{tabular}{|c|c|c|c|c|c|c|c|c|c|}
\hline \multirow{2}{*}{ Index } & \multicolumn{9}{|c|}{ Biomass components } \\
\hline & $P t$ & $P a$ & $P c$ & $P f$ & $P b$ & $\operatorname{Pr}$ & Ps & $P w$ & $P b k$ \\
\hline \multicolumn{10}{|c|}{ Independent equations } \\
\hline$R^{2}$ & 0.746 & 0.798 & 0.571 & 0.292 & 0.570 & 0.249 & 0.803 & 0.856 & 0.643 \\
\hline \multicolumn{10}{|c|}{ Additive equations } \\
\hline$R^{2}$ & 0.746 & 0.799 & 0.571 & 0.293 & 0.571 & 0.238 & 0.804 & 0.871 & 0.660 \\
\hline
\end{tabular}

Table 7. Characteristics of auxiliary recursive equations for mass-forming indices

\begin{tabular}{|c|c|c|c|c|c|c|c|c|c|c|}
\hline $\begin{array}{l}\text { Mass- } \\
\text { forming }\end{array}$ & & Indepen & dent var & les and & he regress & n coeffic & nts of th & model & & $\operatorname{adj} R^{2}$ \\
\hline$H$ & -15.9489 & $8.6068 \ln A$ & - & - & $\begin{array}{c}-1.9231 \\
X 1\end{array}$ & $\begin{array}{c}0.4346 \\
X 2\end{array}$ & $\begin{array}{c}-3.5626 \\
X 3\end{array}$ & $\begin{array}{c}-5.3695 \\
X 4\end{array}$ & $\begin{array}{c}-8.6083 \\
X 5\end{array}$ & 0.768 \\
\hline $\ln D$ & -1.0586 & $0.3531 \ln A$ & $\begin{array}{c}0.9160 \\
\ln H\end{array}$ & - & $\begin{array}{c}-0.0426 \\
X 1\end{array}$ & $\begin{array}{c}-0.0567 \\
X 2\end{array}$ & $\begin{array}{c}0.1867 \\
X 3\end{array}$ & $\begin{array}{c}-0.1181 \\
X 4\end{array}$ & $\begin{array}{c}-0.0180 \\
X 5\end{array}$ & 0.936 \\
\hline $\ln N$ & 3.9068 & $-0.0184 \ln A$ & $\begin{array}{c}0.6613 \\
\ln H\end{array}$ & $\begin{array}{c}-1.9590 \\
\ln D\end{array}$ & $0.0798 \times 1$ & $\begin{array}{c}-0.0923 \\
X 2\end{array}$ & $\begin{array}{c}-0.2702 \\
X 3\end{array}$ & $0.4303 X 4$ & $0.4947 X 5$ & 0.913 \\
\hline
\end{tabular}

Table 8. Fragment of additive transcontinental table of Quercus stand biomass for the age of 60 years, localized on the ecoregions of Eurasia

\begin{tabular}{|c|c|c|c|c|c|c|c|c|c|c|c|c|c|}
\hline \multirow{2}{*}{$\begin{array}{l}\text { Eco- } \\
\text { region }\end{array}$} & \multirow{2}{*}{$\begin{array}{l}\text { Species } \\
\text { of Quercus }\end{array}$} & \multirow{2}{*}{$H, \mathbf{m}$} & \multirow{2}{*}{$\begin{array}{l}D, \\
\mathrm{~cm}\end{array}$} & \multirow{2}{*}{$\begin{array}{c}N, \\
1000 / \\
\text { ha }\end{array}$} & \multicolumn{9}{|c|}{ Stand biomass, $t / h a$} \\
\hline & & & & & $P t$ & $P a$ & $P c$ & $P f$ & $P b$ & $P r$ & $P s$ & $P w$ & Pbk \\
\hline WCE & Q. robur $\mathrm{L}$. & 19.3 & 22.5 & 0.774 & 193.7 & 164.1 & 30.3 & 3.5 & 26.8 & 29.7 & 133.8 & 113.9 & 19.9 \\
\hline WCE & $\begin{array}{l}\text { Q. petraea } \\
\text { (Matt.) Liebl. }\end{array}$ & 17.4 & 19.6 & 1.027 & 224.4 & 185.1 & 40.3 & 4.4 & 35.9 & 39.2 & 144.8 & 125.9 & 18.9 \\
\hline ERn & Q. robur $\mathrm{L}$ & 19.7 & 21.7 & 0.769 & 212.6 & 174.0 & 30.6 & 3.9 & 26.7 & 38.6 & 143.4 & 125.8 & 17.6 \\
\hline ERs & Q. robur $\mathrm{L}$ & 15.7 & 22.5 & 0.517 & 242.4 & 141.8 & 27.5 & 3.3 & 24.2 & 100.6 & 114.2 & 102.7 & 11.6 \\
\hline SFE & $\begin{array}{l}\text { Q. mongolica } \\
\text { Fisch. ex } \\
\text { Ledeb. }\end{array}$ & 13.9 & 14.8 & 2.172 & 218.9 & 151.4 & 26.3 & 4.6 & 21.6 & 67.6 & 125.1 & 102.8 & 22.3 \\
\hline Jap & $\begin{array}{c}\text { Quercus } \\
\text { mongolica } \\
\text { subsp. crisp- } \\
\text { ula (Blume) } \\
\text { Menitsky } \\
\text { Q. glauca } \\
\text { Thunb. }\end{array}$ & 10.7 & 12.9 & 2.570 & 320.9 & 246.4 & 60.3 & 6.5 & 53.8 & 74.5 & 186.1 & 165.9 & 20.1 \\
\hline
\end{tabular}




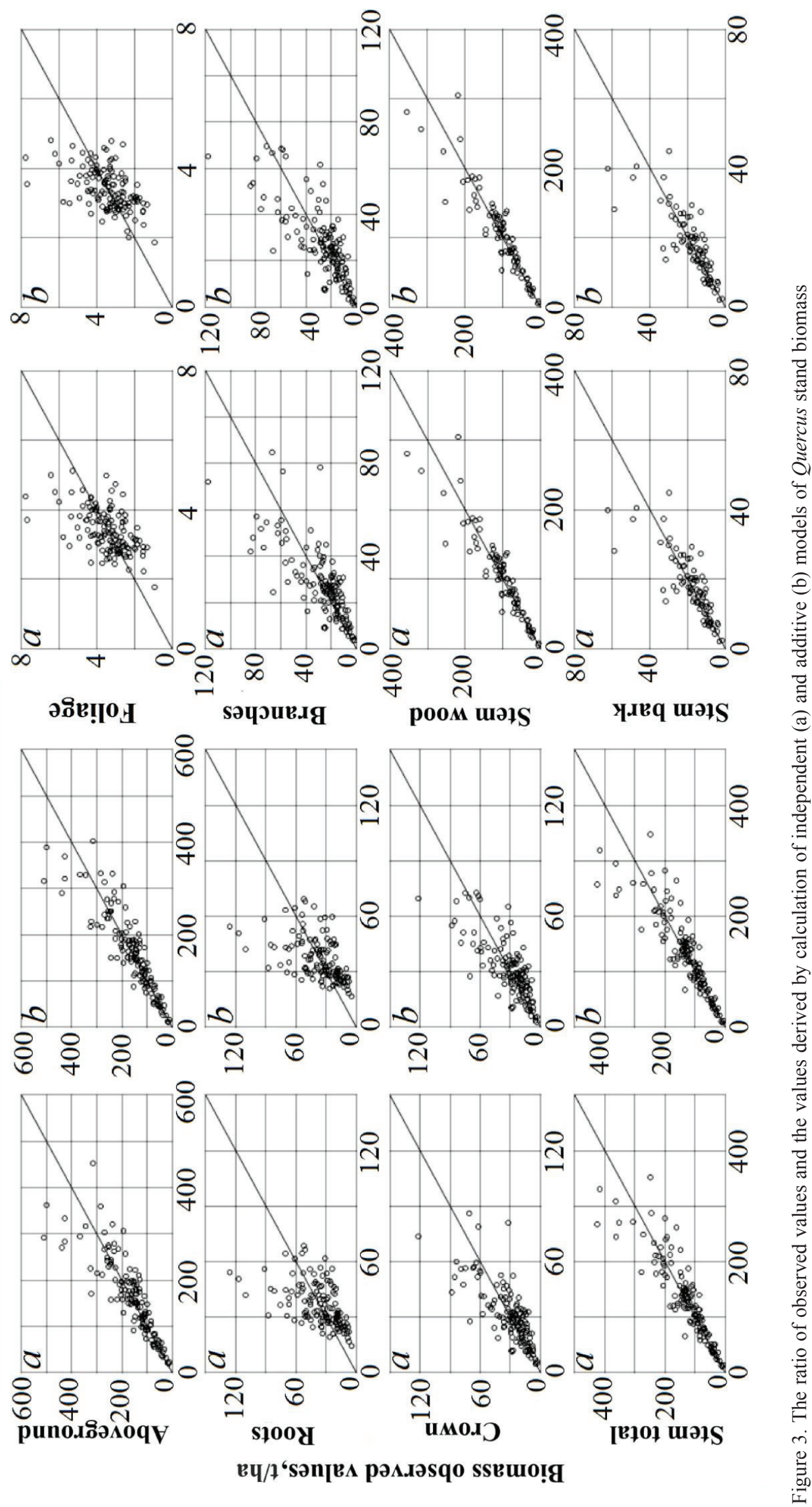


The additive model built (Table 4) includes four numeric independent variables. When its tabulating, there is a problem, which is that we can know and give the value of stand age only of four variables, and the remaining three variables can be entered into the table in the form of calculated values obtained by the system of auxiliary recursive equations (Usoltsev, 1989). Such equations are approximated using the original data and are shown in the Table 7.

The results of sequential tabulations of the equations of the Tables 7 and 4 give the unacceptably voluminous table, the size of which exceeds the format of journal article. Therefore, a comparative analysis of the biomass structure of Quercus stands of different ecoregions we limit by the stand age of 60 years (Table 8). According to the Table 8, the greatest values of total biomass $(321 \mathrm{t} / \mathrm{ha})$ correspond to oak forests $Q$. crispula and $Q$. glauca in Japan, and the lowest (194 t/ha) - to stands of oak forests $Q$. robur in West Europe. The intermediate position in terms of total biomass (213-242 t/ha) is occupied by oak stands in other ecoregions.

The biomass indices of different ecoregions differed not only in absolute value but also in biomass ratios of different components; for example, the proportion of foliage in the aboveground biomass is maximum (2.6-3.0\%) at oak forests of Primorie and Japan, and minimum one (2.1\%) in oak forests of Western and central Europe, and in other regions it is at a stable level of $2.2-2.4 \%$.

\section{Conclusions}

When using the unique in terms of the volume of database on the level of a stand of the genus Quercus, the trans-Eurasian additive allometric model of biomass for oak forests is developed for the first time, and thereby the combined problem of model additivity and generality is solved. The model is harmonized in two levels, one of which provides the principle of additivity of biomass components, and the second one is associated with the introduction of dummy independent variables localizing model according to ecoregions of Eurasia. The proposed model and corresponding table for estimating stand biomass make them possible to calculate Quercus stand biomass on Eurasian forests when using measuring taxation.

\section{Acknowledgments}

We thank the anonymous referees for their useful suggestions. This paper is fulfilled according to the programs of current scientific research of the Ural Forest Engineering University and Botanical Garden of the Ural Branch of Russian Academy of Sciences.

\section{References}

Baskerville G.L., 1972, Use of logarithmic regression in the estimation of plant biomass. Canadian Journal of Forest Research 2: 49-53.

Bi H., Long Y., Turner J., Lei Y., Snowdon P., Li Y., Harper R., Zerihun A. \& Ximenes F., 2010, Additive prediction of aboveground biomass for Pinus radiata (D. Don) plantations. Forest Ecology and Management 259: 2301-2314.

Budyko M.I., 1977, Global ecology. "Mysl” Publishing, Moscow, $328 \mathrm{pp}$.

De-Miguel S., Mehtätalo L. \& Durkaya A., 2014, Developing generalized, calibratable, mixed-effects metamodels for large-scale biomass prediction. Canadian Journal of Forest Research 44: 648-656.

Dong L., Zhang L. \& Li F., 2015, A three-step proportional weighting system of nonlinear biomass equations. Forest Science 61(1): 35-45.

Fu L.Y., Zeng W.S., Tang S.Z., Sharma R.P. \& Li H.K., 2012, Using linear mixed model and dummy variable model approaches to construct compatible single-tree biomass equations at different scales - A case study for Masson pine in Southern China. Journal of Forest Science 58(3): 101-115.

Jacobs M.W. \& Cunia T., 1980, Use of dummy variables to harmonize tree biomass tables. Canadian Journal of Forest Research 10(4): 483-490.

Tang S., Zhang H. \& Xu H., 2000, Study on establish and estimate method of compatible biomass model. Scientia Silvae Sinica 36: 19-27 (in Chinese with English abstract).

Usoltsev V.A., 1989, Recurrent regression system as a base for tree and stand biomass tables, [in:] Proceedings of the IUFRO Project Group P3.05-00 Meeting "Harvesting and utilization of tree foliage", Riga, 217-245 pp. Available from: LVMI Silava: Rīgas iela 111, Salaspils LV-2169 Latvia.

Usoltsev V.A., 2010, Eurasian forest biomass and primary production data. Ural Branch of Russian Academy of Sciences, Yekaterinburg, 574 pp. http://elar.usfeu.ru/ handle/123456789/2606

Usoltsev V.A., 2013, Forest biomass and primary production database for Eurasia. CD-version. The second edition, enlarged and re-harmonized. Ural State Forest Engineering University, Yekaterinburg. http://elar. usfeu.ru/handle/123456789/3059

World Flora Online. An Outline Flora of All Known Plants. http://www.worldfloraonline.org 